\title{
Model Manajemen Fundrising Wakaf di Surabaya (Studi di Yayasan Dana Sosial Al-Falah, Perbandingan Wakaf Selangor, BWI dan Wakaf Global)
}

\author{
Lailiyah Qotrunnada \\ Universitas Islam Negeri Sunan Ampel Surabaya, Indonesia \\ lailiyahqotrunnada@gmail.com \\ Muchammad Saifuddin \\ Universitas Islam Negri Sunan Ampel Surabaya, Indonesia \\ saifuddin@uinsby.ac.id
}

\begin{abstract}
This study is motivated by the low understanding of the community towards waqf and the large potential of waqf. The purpose of this study was to analyze the development of the fundraising strategy carried out by four waqf management institutions. Namely the Surabaya Al-Falah Social Fund Foundation, the Comparison of the Selangor Waqf (PWS), the Indonesian Waqf Board and the Global Waqf. The research method used is through a descriptive qualitative approach with library research data collection techniques. The results showed that the waqf strategy implemented by the four institutions had progressed from the model that YDSF did to raise funds with the Research Funding method which promotes the creation of business results through the development of waqf assets. PWS and BWI are using the same method, namely picking up the ball and waiting for the ball by working together through the Islamic Financial Institution. And the fundamental strategy that can help waqf institutions in the development of information technology is carried out by the Global Waqf Institution, which applies online waqf with an online waqf strategy through the website, transferring accounts and not setting targets. So that the management of waqf can be said to be effective with the existence of several strategies that are best for the success of the institution to achieve its goals.
\end{abstract}

Keywords: fundrising, waqf, al-falah surabaya

\section{Latar Belakang}

Wakaf merupakan muamalah maliyah yang sudah dikenal masyarakat sejak dahulu. Karena Allah SWT sudah menciptakan 
manusia untuk mencintai kebaikan dan melakukannya sejak ia dilahirkan hingga hidup ditengah-tengah masyarakat. Dalam kaitan ini, wakaf merupakan pranata keagamaan yang memiliki kaitan secara fungsional dengan upaya pemecahan masalah-masalah sosial dan kemanusiaan, seperti pengentasan kemiskinan, peningkatan sumber daya manusia dan pemberdayaan ekonomi umat.

Wakaf ini juga memiliki titik terang dalam menanggulangi perekonomian di Indonesia meskipun belum bisa menghapuskan angka kemiskinan yang ada dan belum merata dalam pemberian pemanfaatannya, tetapi wakaf memberikan harapan bagi mauquf alaih dalam pemenuhan kehidupannya. Hal ini juga dibenarkan melalui ayatayat Al-Quran yang artinya bila ditafsirkan mengarah pada perwakafan meskipun tidak jelas- jelas menyebutkan kata-kata wakaf didalamnya.

Berkaitan dengan pengelolaan wakaf, penggalangan terkait sumber daya yang professional dalam penghimpunan wakaf sangat bervariasi dan seringkali berubah searah dengan berkembangnya waktu. Aktivitas fundrising (menghimpun dana/sumber daya) dapat diartikan suatu kegiatan penggalangan dana dan daya lainnya dari masyarakat yang digunakan untuk membiayai ide, program, dan gagasan yang akan diberikan kepada masyarakat penerima kemanfaatan wakaf. Sehingga dalam kegiatan ini dapat menumbuhkan kepercayaan dan hubungan pada masyarakat.

Dari paparan diatas dapat terlihat bahwa fundrising merupakan kegiatan penting yang dilakukan oleh lembaga wakaf. Dalam strateginya perlu dikaji lebih lanjut sebab fundrising sangat berpotensi dalam upaya peningkatan produktivitas pengelolaan khususnya penghimpunan aset wakaf.

\section{Kajian Teori}

\section{Indikator Efektifitas}

Efektivitas berasal dari kata efektif dari kata serapan bahasa inggris effect yang artinya perilaku atau reaksi dari seseorang yang sedang diamati, berhasil atau tidaknya sesuatu yang dilakukan. Efektivitas merupakan teori yang menghubungkan bahwa efektivitas organisasi/kegiatan berpengaruh pada tingkat kepuasan, sehingga dalam definisi ini dikatakan efektif apabila orang-orag yang terkait merasa puas dengan kinerja lembaga karena pandangan ini sebagai inti persoalan organisasi. ${ }^{1}$

Konsep efektivitas digunakan sebagai upaya mengevaluasi

\footnotetext{
${ }^{1}$ Indrawijaya, A. I. Teori, Perilaku, dan Budaya Organisasi. Ali Mifka, (Ed.) Bandung: PT. Refika Aditama, 2010, 198-201.
} 
jalannya suatu organisasi/lembaga terhadap suatu program yang dilakukan sesuai dengan tujuannya apakah program yang dijalankan tersebut mengalami peningkatan yang baik atau justru sebaliknya. ${ }^{2} \mathrm{Hal}$ tersebut penting peranannya didalam setiap lembaga atau organisasi dan berguna untuk melihat perkembangan dan kemajuan yang dicapai oleh suatu lembaga atau organisasi. Oleh karena itu salah satu tujuan dalam efektivitas yaitu untuk memonitor progresivitas agar lebih terukur. Sebab semakin besar persentase target yang dicapai, maka semakin tinggi efektivitasnya.

\section{Pengertian Wakaf}

Secara etimologi, waqaf berasal dari kata waqafa-yaqifu-waqfan yang berarti berhenti, berdiri ditempat atau menahan. ${ }^{3}$ Sedangkan menurut terminologi wakaf mempunyai banyak istilah yang diungkapkan oleh para ulama: Pertama, menurut al- jazairi wakaf adalah penahanan harta sehingga harta tersebut tidak bisa diwarisi, atau dijual atau dihibahkan dan mendermakan hasilnya kepada penerima wakaf. Kedua, menurut madzhab umum yaitu madzhab Syafi'i wakaf adalah menahan harta yang dapat diambil manfaatnya dengan tetap utuhnya barang dan barang tersebut hilang kepemilikannya dari waqif, serta dimanfaatkan pada sesuatu yang diperbolehkan. ${ }^{4}$

Sedangkan wakaf menurut Undang-undang Nomor 41 Tahun 2004 adalah perbuatan seseorang atau badan hukum yang memisahkan sebagian harta benda miliknya untuk dimanfaatkan dalam jangka waktu tertentu atau selamanya sesuai dengan kepentingan dan kesejahteraan umat sesuai syariat. ${ }^{5}$

Dari beberapa pengertian ini dapat difahami bahwa wakaf adalah perbuatan seseorang untuk memisahkan harta benda miliknya untuk dimanfaatkan dalam kepentingan ibadah dan kesejahteraan umum. Perlu dipahami dari perbedaan pendapat tersebut memberikan kelonggaran pemikiran bagi para ulama untuk memilih salah satu dari pendapat tersebut dalam pengembangan dan pemberdayaan wakaf produktif di Indonesia. ${ }^{6}$ Tidak hanya pemahaman dalam teks saja

2 A. Damanuri (2016) "Efektivitas dan Efesiensi Pemanfaatan Harta Wakaf Majlis Wwakaf Pimpinan Daerah Muhamadiyah Ponorogo", Jurnal Kodifikasia, 6 (1), 77-98.

3 Muhammad Daud Ali, Sistem Ekonomi Islam: Zakat dan Wakaf, Cet.1. Jakarta: Penerbit Universitas Indonesia, 1988, 180-181.

${ }^{4}$ A. Atabik (2014) "Manajemen Pengelolaan Wakaf Tunai diIndonesia", Jurnal Zakat dan Wakaf, 1 (1), 83-107.

${ }^{5}$ Fakhruddin (2019) "Pengaruh Mazhab dalam Regulasi Wakaf di Indonesia”, Jurisdictie: Jurnal Hukum dan Syariah, 10(2), 252-256

${ }^{6}$ Veitzal Rivai Zainal (2016) “Pengelolaan dan Pengembangan Wakaf Produktif”, Jurnal al-Awqaf, 
melainkan pemahaman dalam kondisi masyarakat.

Sumber hukum utama dalam hukum Islam adalah Al-Quran dan As-Sunnah atau Al- Hadits. Mengenai masalah wakaf tidak dengan tegas disebutkan dalam Al-Quran, namun beberapa ayat Al-Quran memberi petunjuk dan dapat dijadikan rujukan sebagai sumber hukum perwakafan. ${ }^{7}$ Berdasarkan firman Allah Subhanahu wa Ta'ala yaitu dalam Surat Al-Imran ayat 92:

Kamu sekali-kali tidak sampai kepada kebajikan (yang sempurna), sebelum kamu menafkahkan sebagian harta yang kamu cintai. Dan apa saja yang kamu nafkahkan maka sesungguhnya Allah mengetahuinya (QS. Al Imran:92).

Dalam ayat ini terdapat anjuran untuk melakukan infak secara umum terhadap sebagian dari apa yang dimiliki seseorang, dan termasuk ke dalam pengertian umum infak menurut jumhur ulama adalah melalui sarana wakaf. ${ }^{8}$ Dalam ayat lain Allah Ta'ala berfirman:

Berimanlah kamu kepada Allah dan Rasul-Nya dan nafkahkanlah sebagian dari hartamu yang Allah telah menjadikan kamu menguasainya. Maka orang-orang yang beriman di antara kamu dan menafkahkan (sebagian) dari hartanya memperoleh pahala yang besar (QS. Al Hadiid: 7).

Terdapat pula dalam hadits Rasulullah Shallallahu 'alaihi wa sallam yang tercermin dari praktik wakaf yang dilakukan oleh Umar bin Khatthab. Pada saat Umar bin Khatthab mendapatkan sebidang tanah pada perang Khaibar dan tanah tersebut sangat bermanfaat baginya, beliau radhiallahu 'anhu kemudian mendatangi Rasulullah Shallallahu 'alaihi wa sallam dan meminta arahan Nabi. Kemudian beliau Shallallahu 'alaihi wa sallam menyarankan Umar untuk mewakafkan hartanya dengan bersabda:

"Jika engkau mau, engkau dapat menahan barangnya dan menyedekahkan hasilnya." (HR. Bukhari, No. 2737). Umar bin Khatthab melakukannya dan menentukan pihak yang mendapatkannya (Shahih Bukhari, n.d.).

Selain dasar dari al-quran dan hadits di atas, para ulama dan ahli fiqih sepakat (ijma') menerima wakaf sebagai satu amal jariah yang

$9(1), 1-16$.

7 J. Abdullah; N. Qadin (2014) “Aspek Hukum Penggunaan Teknologi Informasi dalam Wakaf Uang di Indonsesia", Jurnal ZISWAF, 1 (2), 273-292.

${ }^{8}$ Makhrus Ahmadi (2017) “Pengembangan Dana Zakat, Infak, Shadaqah dan Wakaf terhadap Pertumbuhan Industri Keuangan Non Bank Syariah", Jurnal Masharif al-Syariah, 2(2), 1-15. 
disyariatkan dalam Islam. Sejak masa Khulafaur Rasyidin sampai sekarang, dalam membahas dan mengembangkan hukum- hukum wakaf melalui ijtihad mereka. ${ }^{9}$ Sebab itu sebagian besar hukumhukum wakaf dalam Islam ditetapkan sebagai hasil ijtihad, dengan menggunakan metode ijtihad yang bermacam-macam, seperti qiyas dan lain-lain. ${ }^{10}$

\section{Strategi Fundrising Wakaf}

Strategi fundrising terdiri dari dua kata yaitu strategi dan fundrising. Webster's New World Dictionary mendefinisikan strategi sebagai sebuah keterampilan dalam merencanakan dan mengelola organisasi atau cara cerdik untuk mencapai tujuan. Strategi adalah kunci dari terlaksananya misi organisasi dalam program yang dikelola agar bisa meningkatkan kemampuan bertahan dan juga sebagai alat penting dalam organisasi yang berkomitmen pada kualitas dan efektivitas. ${ }^{11}$

Fundrising merupakan pengumpulan dana. Fundrising didefinisikan sebagai kegiatan menghimpun dana dari masyarakat (baik individu, kelompok, organisasi, perusahaan ataupupun pemerintah) dan sumber daya lainnya. ${ }^{12}$ Adanya strategi fundrising mempunyai tujuan dan unsur fundrising agar lembaga pengelola wakaf bisa memaksimalkan misi yang direncanakan. Diantaranya Pengumpulan dana. ${ }^{13}$ Dana yang dimaksudnya disini bukanlah uang saja, tetapi dana dalam arti luas. Termasuk di dalamnya barang dan atau jasa yang memiliki nilai materi. Menghimpun para wakif. Badan wakaf yang baik adalah badan wakaf yang setiap hari memiliki data pertambahan wakif.

Dengan bertambahnya wakif secara otomatis akan bertambah pula jumlah dana yang terhimpun. Meningkatkan citra lembaga badan wakaf. ${ }^{14}$ Aktivitas fundraising yang dilakukan oleh sebuah organisasi pengelola badan wakaf, baik langsung maupun tidak langsung akan membentuk citra organisasi itu sendiri. Ketika sebuah badan wakaf

\footnotetext{
${ }^{9}$ Ahmad Muslich (2017), "Peluang dan Tantangan dalam Pengelolaan Wakaf", Jurnal Muaddib, 6(2), 4-9.

10 Kementrian Agama Republik Indonesia, Direktorat Jenderal Bimbingan Masyarakat Islam, 2006, 78-79.

11 R. Listiyaningrum. Strategi Fundrising Yayasan Kesejahteraan Tuna Netra Islam. Yogyakarta: Kanisius 2015, 23-25.

12 Jauhar Faradis; M. Yazid Affandi; Slamet Khilmi (2017), “Manajemen Fundraising Wakaf Produktif: Perbandingan Wakaf Selangor (PWS) Malaysia dan Badan Wakaf", Asy-Syir'ah, 500505.

${ }^{13}$ Abdul Haris Naim (2019), "Lembaga Pengelola Wakaf dan Manajemen Fundraising", Jurnal Zizwaf, 6(1), 17-19.

${ }^{14}$ Hendi Suhendi (2018), “Optimalisasi Aset Wakaf sebagai Sumber Dana Pesantren melalui Pelembagaan Wakaf", Tahkim, 1(1), 1-20.
} 
melakukan penghimpunan dana wakaf, maka ada tujuan jangka panjang untuk menjaga loyalitas wakif agar tetap memberikan sumbangan dana wakafnya kepada badan wakaf. ${ }^{15}$ Unsur-unsur fundraising ini ada beberapa hal yang penting, seperti kebutuhan wakif, segmentasi pasar, posisi pasar terhadap pesaing, produk yang ditawarkan untuk memenuhi kebutuhan konsumen, harga dan biaya transaksi bagi seorang wakif yang menikmai jasa penyaluran wakaf, promosi, dan maitance atau bisa dikatakan menjalin hubungan yga baik dengan wakif. ${ }^{16}$

\section{Metode Penelitian}

Penelitian dengan judul "efektivitas penerapan strategi fundrising dalam upaya optimalisasi pengelolaan dana wakaf" menggunakan pendekatan kualitatif yang bisa dilihat dengan metode deskriptif analitis. Karena penelitian ini menghasilkan data deskriptif yang berupa kata-kata tertulis atau lisan dari orang-orang dan perilaku yang diamati.

Teknik pengumpulan data yang digunakan dalam penelitian ini disesuaikan dengan fokus dan tujuan penelitian yaitu menggunakan studi pustaka (Library Research). Studi pustaka adalah penelitian yang dilakukan oleh peneliti dengan mengumpulkan sejumla buku-buku, majalah, liflrt, yang berkenaan dengan masalah dan tujuan penelitian. Buku tersebut dianggap sebagai sumber data yang akan dianalisis seperti yang dilakukan oleh ahli sejarah, sastra dan bahasa. Studi pustaka merupakan istilah lain dari kajian pustaka, tinjauan pustaka, kajian teoritis, landasan teori, telaah pustaka (literature review), dan tinjauan teoritis. Yang dimaksud penelitian kepustakaan adalah penelitian yang dilakukan hanya berdasarkan atas karya tertulis, termasuk hasil penelitian baik yang telah maupun yang belum dipublikasikan. ${ }^{1}$

Meskipun dikatakan sebuah penelitian, tetapi penelitian studi literatur tidak harus turun ke lapangan bertemu responden. Data-data yang dibutuhkan dalam penelitian dapat diperoleh dari sumber pustaka atau dokumen. Menurut Zed,2014 pada riset pustaka (library research), penulusuran pustaka tidak hanya untuk langkah awal menyiapkan kerangka penelitian akan tetapi sekaligus memanfaatkan sumber-

\footnotetext{
${ }^{15}$ M. Guffar Harahap (2019), "Strategi Fundrasing Wakaf di Badan Wakaf Pondok Pesantren Mawaridussalam", Jurnal at-Tawassuth, IV(2), 1-5.

16 April Purwanto, Manajemen Fundrising bagi Organisasi Pengelolaan Zakat. Yogyakarta: Teras, 2009, 67-77.
} 
sumber perpustakaan untuk memperoleh data penelitian. ${ }^{17}$

\section{Hasil Penelitian \\ Model Manajemen Fundrising Wakaf di yayasan Dana Sosial al-Falah Surabaya}

Yayasan Dana Sosial Al-Falah atau biasa dikenal YDSF Surabaya ini merupakan lembaga filantropi yang tertua dalam mengelola zakat, infaq, sedekah dan wakaf nasional yang sudah terpercaya dan selalu mengutamakan kepuasan donatur. Dalam konteks pengelolaan YDSF selalu mengembangkan pola manajemen yang bermutu untuk mengembangkan visi dan misi, paradigma organisasi, sistem manajemen dan pardigma program YDSF.

Model fundrising wakaf YDSF tidak identik hanya menghimpun dana tetapi ruang lingkupnya lebih luas dan berpengaruh pada eksistensi pertumbuhan sebuah lembaga. Mekanisme kerja fundrising wakaf melalui beberapa tahapan manajemen dan aktivitasnya tidak hanya menghimpun dan mengumpulkan dana tetapi juga untuk menghasilkan pola aset wakaf yang produktif baik secara financial maupun nonfinancial. ${ }^{18}$

Adapun metode yang dilakukan YDSF dalam fundrising adalah research fundrising. Dilihat dari metode penggalangan dana melalui programnya yang dipilih, seperti program rumah cinta yatim, pena bangsa, kemanusiaan dan program lainnya. Sedangkan model fundrising wakaf secara umum dikelompokkan menjadi: program intensifikasi, eksentifikasi dan program layanan donatur atau wakif.

Mengenai mekanisme kerja fundrising wakaf yang dilakukan YDSF berkembang secara produktif dan menghasilkan, baik berupa financial maupun non financial yang tertera dalam konteks resource fundrising (secara langsung atau tidak langsung), dan grant fundrising dengan metode penguatan program pemberdayaan pada penyaluran wakaf. Sedangkan dalam aset fundrising (wakaf) YDSF belum dapat mengembangkannya atau memproduktifkan aset. Realitanya YDSF ini melakukan kegiatan fundrising wakaf produktif dan berkembang ketika YDSF lebih mengedepankan dan kuat dalam memobilisasi sumber daya/dana wakaf melalui penciptaan hasil usaha lewat pengembangan aset wakaf.

${ }^{17}$ Zed, M, Metode Penelitian Kepustakaan, Jakarta: Yayasan Obor Indonesia, 2014, 67-69.

${ }^{18}$ Miftahul Huda (2019) "Model Manajemen Fundrising Wakaf", Jurnal Ahkam, XIII (1), 89-90. 


\section{Manajemen Fundrising Wakaf}

Efektivitas dan efisiensi penghimpunan dana wakaf sangat pengaruh kepada kinerja pengurus badan wakaf. Pelaksanaan strategi fundrising wakaf yang dilakukan PWS dan BWI menggunakan dua metode yang sama, yaitu metode menunggu bola dan metode jemput bola. ${ }^{19}$

Pertama, Metode "menunggu bola" dalam konsepan Badan Wakaf Indonesia (BWI) yaitu Pengurus menunggu wakif yang dengan sukarela menyerahkan sebagian hartanya untuk diwakafkan. Diawali membuka rekening yang bekerjasama dengan lembaga Keuangan Syariah di seluruh Indonesia seperti pada bank-bank syariah sebagai penerima wakaf uang atas nama BWI. Kelemahan dari konsepan tersebut Lembaga Keuangan Syariah hanya menjadi nadzir penerima dan penyalur sedangkan pengelolaan dilakukan oleh BWI. Sehingga berdampak pada lambatnya penyaluran dana wakaf. Selain itu dalam penghimpunan maupun pengelolaannya menggunakan aset-aset wakaf yang sudah ada kemudian diproduktifkan. Seperti Masjid Baitul Mughi Gatot Subroto, Masjid Naum Tanah Abang, Masjid Hidayatullah Sudirman dan lain sebagainya.

Sementara penghimpunan dana wakaf yang dilakukan PWS hampir sama dengan konsep fundrising yang dilakukan BWI yaitu menunggu wakif yang sukarela menyerahkan hartanya di Lembaga Keuangan Syariah PWS. Tetapi metode "menunggu bola" yang dilakukan PWS diawali dengan membuka kaunter PWS, Skim Infaq (Potong gaji), Ejen, dan Portal e-Mais. Selain bekerjasama dengan Lembaga Keuangan Syariah untuk mempermudah wakif untuk mewakafkan uangnya, PWS juga bekerjasama dengan lembaga pendidikan seperti University Kebangsaan Malaysia, University Putra Malaysia dan Universitas Antar Bangsa Selangor. Yang menjadi kekuatan terbesar yang dimiliki PWS dalam fundrising yaitu adanya Duta Wakaf dan peran pemerintah dalam hal wakaf sebagai pengurang pajak sesuai dengan peraturan LHDN.01/35/42/51/179-6.5621 dan Warta Kerajaan 14639 bertarikh 27.07.2004.

Kedua, penghimpunan dengan metode "Jemput Bola". Pengurus BWI dan PWS memiliki kesamaan berperan proaktif untuk mendapatkan calon wakfi yaitu dengan mendatangi instansi-instansi pemerintah maupun swasta untuk mensosialisasikan wakaf dan

19 Jauhar; M. Yazid; Slamet (2016) “Manajemen Fundraising Wakaf Produktif: Perbandingan Wakaf Selangor (PWS) Malaysia dan Badan Wakaf Indonesia, Jurnal Ilmu Syariah dan Hukum, 49 (2), 12-15. 
memotivasi masyarakat untuk berpatisipasi menjadi wakif dengan sistem pemotongan sekian persen dalam gaji sesuai dengan keikhlasan mereka. Kekuatan terbesar dari BWI karena adanya interaksi langsung terhadap masyarakat sehingga ada kesepatan dalam pemotongan gaji yang dihimpun oleh bendahara instansi dan disetor ke BWI setiap bulannya dengan atas nama instansi terkait. Meski usaha yang dilakukan BWI sudah msksimal tetapi ada kelemahan dalam kelsulitan beradaptasi karena sulitnya memberi pemahaman pada masyarakat mengenai wakaf tunai.

Adapun model yang dipakai PWS dalam metode ini yang pertama, Bulan wanita dan Wakaf, program ini dilaksanakan pada bulan Maret sampai April dalam bentuk wakaf emas baik secara wakaf tetap maupun sementara. Kedua, Bulan Wakaf Selangor, program yang dilakukan pada bulan Rajab, Sya'ban dan Ramadhan melihat aspek spritual yang diartikan sedekah karena suatu amal seseorang berlipat ganda pahalanya jika dibuat untuk memberi kemanfaatan orang lain. Ketiga, Bulan Masre Industri. Model ini dilaksanakan pada bulan Oktober, November dan Desember. Dilakukan setiap akhir tahun karena syarikat (Korporat) akan melakukan tutup tahun. Sehingga memicu syarikat untuk berwakaf yang dapat mengurangi pajak (cukai) sebesar 10\%. Dan keempat, Membentuk duta wakaf yang diisi oleh Ustadz Don Daniyal Don Biyajid sebagai duta dalam pelaksanaan sosialisasi pengenalan wakaf PWS.

Pada perkembangannya, kedua metode yang dilakukan oleh dua lembaga tersebut mengalami peningkatan yang baik. Dengan berbagai proses sosialisasi dalam forum resmi maupun tidak resmi di seluruh wilayah Indonesia dan wilayah Selangor Malaysia. Jumlah dana wakaf uang-tunai yang terkumpul mengalami peningkatan yang terdiri dari hasil wakaf am, wakaf khas, hartanah wakaf dan manfaat wakaf.

\section{Efektifitas Strategi Fundrising Wakaf Berbasis Online}

Global Wakaf Foundation merupakan lembaga pengelola wakaf dari masyarakat yang mengelola wakaf yang bertujuan membangun kesejahteraan masyarakat yang berhak menerimanya melalui programprogram yang terutama bersifat memberdayakan (produktif). Global Wakaf Foundation sebagai lembaga wakaf yang memiliki layanan wakaf online terpercaya yang mengelola dana wakaf secara profesional, amanah, berjangkauan luas (global) dan transparan. ${ }^{20}$ Mengenai strategi fundrising yang dilakukan global wakaf dari segi

${ }^{20}$ S. Aisyah Ekawati (2018) "Efektivitas Strategi Fundraising wakaf berbasis wakaf online di Global wakaf Aksi Cepat Tanggap Yogyakarta", Jurnal De Jure, 4(1), 56-58. 
aksi cepat tanggap ada beberapa tahapan. Tahap pertama adalah persiapan mengenai program wakaf online. Lembaga yang merubah dari strategi tradisional ke profesional yaitu dengan metode online agar masyarakat bisa meningkatkan pengetahuan mengenai wakaf yg modern tanpa menganggap wakaf hanya dg benda tak bergerak dan bernominal besar. Dengan program global wakaf menerapkan wakaf online minimal berwakaf hanya Rp. 10.0000,00 bisa menumbuhkan kesadaran berwakaf secara kontinue dengan harta semampunya.

Selanjutnya adalah tahap sosialisasi mengenai layanan wakaf. Global wakaf tidak hanya mensosialisasikan program donasi lewat online dengan media sosial tapi ada jugaperan akun ACT Yogyakarta. Global Wakaf bekerjasama dengan beberapa e-commerse dan ebussiness seperti kitabisa.com, toko pedia, buka lapak dalam bentuk iklan.Bahkan global wakaf ACT mengajak para tokoh publik/artis/influencer untuk turut berpartisipasi sebagai endorsement yang dilakukan secara sukarela atas dasar sosial, kepedulian terhadap sesama dan kemanusiaan.

Beberapa dengan bantuan media seperti iklan, pamflet, brosur, kampanye, banner, spanduk, majalah, event, seminar, kampanye, live report, SMS/Whatsapp, Direct Mail, counter di tempat umum seperti Masjid, dan masih banyak cara lainnya. Sehingga tujuan strategi fundraising selain memperbanyak jumlah donatur/wakif juga meningkatkan citra lembaga di mata masyarakat dalam kata lain kepercayaan, mendapatkan simpatisan atau relasi pendukung sehingga berdampak pada peningkatkan kepuasan wakif yang perlu dijaga dan dipertahankan dalam jangka panjang.Setelah tahap sosialisasi, Pada praktik pelaksanaan wakaf online cukup mudah yaitu dengan mengakses website. Tidak hanya dengan smartphone, wakaf online berbasis website ini dapat diakses melalui browser yang ada di PC (Personal Computer) maupun laptop. Dengan mengisi data diri untuk log in dan mentransfer uang baik lewat mobile banking ataupun ATM.

Efektivitas keberhasilan lembaga pada progresifitas pencapaian tujuannya dan faktor-faktor lain dalam strategi fundraising global wakaf dengan sistem online. Dalam pemasukan dana wakaf melalui proses transfer, ada 2 rekening yaitu rekening ACT dan rekening Global Wakaf. Rasio efektivitas pada tahun 2016 sebesar 7,59\%, tahun 2017 22,52\% dan 2018 18,47\% maka menunjukkan hasil tidak efektif dari segi persentase antara target dengan jumlah perolehan wakaf. selanjutnya tahun $2017 \mathrm{Rp}$ 225.227.071,00 dan tahun 2018 terhitung hingga bulan Juli Rp 369.469.718,00 maka dapat dikatakan efektif seiring dengan peningkatan jumlah perolehan dana wakaf setiap 
tahunnya yang cukup signifikan sejak diberlakukannya wakaf online meskipun pada tahun 2018 presentase menurun karena mengalami kenaikan target.

\section{Kesimpulan}

Berdasarkan penelitian yang telah dilakukan, dapat ditarik kesimpulan bahwa dalam pelaksanaan strategi fundraising oleh lembaga pengelola wakaf dikatakan efektifivitas apabila dari segi persentase antara target dengan jumlah perolehan wakaf seimbang. Model pengelolaan yang dilakukan lembaga berbeda-beda. Dalam tujuan fundrising tidak hanya melkukan penghimpunan dana namun didalamnya adalah peningkatan citra lembaga, memberikan kepuasan donatur dan memperbanyak donatur. Strategi yang dilakukan tersedia dari beragam jenis wakaf dari cara tradisional didesain hingga cara yang modern. Dengan berbagai ragam cara agar lembaga dikatakan amanah, transparansi dan semakin banyak jumlah relasi pendukung untuk menjadi donatur atau wakif. Dari hasil penelitian bisa disimpulkan dengan perkembangan pengelolaan wakaf yang semakin produktif, dengan beberapa strategi yang ada dilembaga diatas ada strategi yang mempermudah wakif dan nadzir yaitu dengan adanya wakaf online. Strategi yang lebih praktis, hemat waktu, dan tenaga kerja serta sangat memudahkan bagi masyarakat yang memiliki kegiatan yang padat sehingga terbentuk kesesuaian antara harapan wakif dengan kinerja nadzir.

\section{Daftar Pustaka}

Ivancevich, J.M. Perilaku dan Manajemen Organisasi. Jakarta: Erlangga, 2007. Indrawijaya, A. I. Teori, Perilaku, dan Budaya Organisasi. Ali Mifka, (Ed.) Bandung: PT. Refika Aditama, 2010.

Damanuri A. (2016) “Efektivitas dan Efesiensi Pemanfaatan Harta Wakaf Majlis Wwakaf Pimpinan Daerah Muhamadiyah Ponorogo", Jurnal Kodifikasia, 6 (1).

Ali, Muhammad Daud., Sistem Ekonomi Islam: Zakat dan Wakaf, Cet.1. Jakarta: Penerbit Universitas Indonesia, 1988.

Atabik A. (2014), "Manajemen Pengelolaan Wakaf Tunai diIndonesia”, Jurnal Zakat dan Wakaf, 1 (1).

Fakhruddin (2019) "Pengaruh Mazhab dalam Regulasi Wakaf di 
Indonesia", Jurisdictie: Jurnal Hukum dan Syariah, 10(2).

Zainal, Veitzal Rivai (2016), "Pengelolaan dan Pengembangan Wakaf Produktif", Jurnal al-Awqaf, 9 (1).

Abdullah, J.; N. Qadin (2014) “Aspek Hukum Penggunaan Teknologi Informasi dalam Wakaf Uang di Indonsesia", Jurnal ZISWAF, 1 (2).

Ahmadi, Makhrus (2017), “Pengembangan Dana Zakat, Infak, Shadaqah dan Wakaf terhadap Pertumbuhan Industri Keuangan Non Bank Syariah", Jurnal Masharif al-Syariah, 2(2).

Muslich, Ahmad. (2017), "Peluang dan Tantangan dalam Pengelolaan Wakaf", Jurnal Muaddib, 6(2).

Kementrian Agama Republik Indonesia, Direktorat Jenderal Bimbingan Masyarakat Islam, 2006.

Listiyaningrum, R. Strategi Fundrising Yayasan Kesejahteraan Tuna Netra Islam. Yogyakarta: Kanisius 2015.

Faradis, Jauhar; M. Yazid Affandi; Slamet Khilmi (2017), “Manajemen Fundraising Wakaf Produktif: Perbandingan Wakaf Selangor (PWS) Malaysia dan Badan Wakaf", Asy-Syir'ah, 2(2).

Naim, Abdul Haris (2019), “Lembaga Pengelola Wakaf dan Manajemen Fundraising", Jurnal Zizwaf, 6(1).

Suhendi, Hendi (2018), “Optimalisasi Aset Wakaf sebagai Sumber Dana Pesantren melalui Pelembagaan Wakaf", Tahkim, 1(1).

Harahap, M. Guffar (2019), "Strategi Fundrasing Wakaf di Badan Wakaf Pondok Pesantren Mawaridussalam", Jurnal at-Tawassuth, IV(2).

Purwanto, April. Manajemen Fundrising bagi Organisasi Pengelolaan Zakat. Yogyakarta: Teras, 2009.

Zed, M, Metode Penelitian Kepustakaan, Jakarta: Yayasan Obor Indonesia, 2014.

Huda, Miftahul (2019) "Model Manajemen Fundrising Wakaf", Jurnal Ahkam, XIII (1).

Jauhar; M. Yazid; Slamet (2016) "Manajemen Fundraising Wakaf Produktif: Perbandingan Wakaf Selangor (PWS) Malaysia dan Badan Wakaf Indonesia, Jurnal Ilmu Syariah dan Hukum, 49 (2).

Aisyah, Ekawati S. (2018) "Efektivitas Strategi Fundraising wakaf berbasis wakaf online di Global wakaf Aksi Cepat Tanggap Yogyakarta", Jurnal De Jure, 4(1). 